\title{
GREThA
}

Groupe de Recherche en

Économie Théorique et Appliquée

\section{Groundwater management in food security context}

\author{
Jean-Christophe Pereau \\ GREThA, CNRS, UMR 5113 \\ Université de Bordeaux \\ jean-christophe.pereau@u-bordeaux.fr
}

$\&$

\section{Lauriane Mouysset}

CNRS, UMR 5113 GREThA \& INRA, UMR 210 Economie Publique lauriane.mouysset@u-bordeaux.fr

$\&$

\section{Luc Doyen}

CNRS, UMR 5113 GREThA

luc.doyen@u-bordeaux.fr

\section{Cahiers du GREThA}

$n^{\circ}$ 2016-14

June

\section{G RETHA UMR C NRS 5113}

Université de Bordeaux

Avenue Léon Duguit - 33608 PESSAC - FRANCE

Tel : +33 (0)5.56.84.25.75 - Fax : +33 (0)5.56.84.86.47 - www.gretha.fr 
Gestion d'un aquifère en présence d'une contrainte de sécurité alimentaire

Résumé

Cet article analyse comment un instrument de marché du type permit transférable permet une gestion soutenable d'un aquifère destiné à satisfaire les besoins en eau d'une agriculture irriguée. Un modèle dynamique hydro-économique est proposé dans lequel une agence de l'eau cherche à garantir une contrainte de production agricole en présence d'exploitants myopes. Le noyau de viabilité qui détermine les trajectoires possibles de prélèvements en fonction de l'état de la ressource et des contraintes fixées est analytiquement calculé. Des simulations numériques reposant sur la calibration proposée par Gisser and Sanchez (1980) illustre les principaux résultats de l'article.

Mots clés: Aquifère, Agriculture, Irrigation, sécurité alimentaire, quotas individuels, Soutenabilité, Systèmes dynamiques, Viabilité.

\title{
Groundwater management in food security context
}

\begin{abstract}
This article studies the sustainability of market-based instrument such as tradable permits for the management of a renewable aquifer used in agriculture production. Based on a dynamic hydroeconomic model, a water agency aims at satisfying a food security constraint within a tradable permit scheme in the presence of myopic heterogeneous agents. We identify analytically the viability kernel that defines the states of the resource yielding inter-temporal feasible paths able to satisfy the set of constraints over time. We then illustrate the results with numerical simulations based on the data from Gisser and Sanchez (1980).
\end{abstract}

Keywords: Groundwater, Agriculture, Irrigation, Food security, Individual permits, Sustainability, Dynamic model, Viability kernel.

JEL: 15, Q25, C61

\begin{tabular}{l} 
Reference to this paper: PEREAU Jean Christophe, MOUYSSET Lauriane, DOYEN Luc (2016) \\
Groundwater management in food security context, Cahiers du GREThA, n²016-14. \\
\hline http://ideas.repec.org/p/grt/wpegrt/2016-14.html.
\end{tabular}




\section{Introduction}

With 20\% of over-exploited aquifers all around the word (WWAP, 2015), groundwater resources are under extreme pressure (Wada et al., 2010). With drinking water, water demand for agriculture remains the main pressure on aquifers, and this pressure continues to grow with the population increase. Indeed, it has been estimated that agriculture will need to produce more than $60 \%$ of food by 2050 as compared to the current situation (FAO, 2014), and will then demand more and more water for irrigation and crop production. To face this potential water crisis, water agencies are mobilized in order to ensure sustainable management of renewable aquifers by limiting the volume of water usable for irrigation. However such a limitation impacts indirectly the agricultural production. The question of sustainable management of renewable aquifers is thus strongly connected to the objective of food security.

The question of sustainable management of renewable water has been investigated in the literature. Notably, the use of transferable permits has been proposed as a promising way to replenish an aquifer (Provencher 1993), or to manage efficiently a groundwater aquifer for irrigated agriculture (Latinopoulos and Sartzetakis, 2015). The process behind this idea is that transferability ensures that water is used by farmers with the highest effectivenesses. As farmers differ in their productivity, economic efficiency implies that an efficient farmer will produce more than a less efficient farmer with the same water volume. In other words, efficiency implies that the total water extraction provides the maximum amount of food production. The crucial role of transferability has also been pointed out by Knapp et al (2003): they showed that transfers between agriculture and urban sectors and/or within a region as well as between regions reaches an efficient management of aquifers. Finally, the success of implementation of transferable quotas in fisheries (Branch, 2008; Chu, 2009; Pereau et al, 2012) calls for the use of individual permits in aquifers since similarities between groundwater and biological renewable resources have been highlighted (Roumasset and Wada, 2012).

This paper aims at addressing the management of water as renewable and limiting resource based on transferable quotas. We develop a dynamic hydro-economic model based on the seminal model of Gisser and Sanchez (1980). The state of art of this literature, including management issues and game theoretical models, has been addressed in Rubio and Casino (2001), Koundouri (2004), Booker et al (2012), Madani and Dinar (2013), Tomini (2014) and De Frutos Cachorro et al (2014). Similarly to Latinopoulos and 
Sartzetakis (2015), we explicitly represent a water management system based on transferable permits among farmers. We extend this model by adding a food security constraint in the design of the water agency policy. This implies that the water agency has to adopt a multi-criteria management approach to balance economic efficiency, agricultural production and the water resource.

The analysis of our hydro-economic model relies on the weak invariance (Aubin, 1990) or viable control method (Clarke et al, 1995). This approach focuses on identifying inter-temporal feasible paths within a set of desirable objectives or constraints (Béné et al, 2001). This framework has already been applied to renewable resources management and especially to the regulation of fisheries (Martinet et al, 2007; Doyen and Pereau, 2012) but its application in groundwater management is completely new.

The paper is structured as follows. Section 2 is devoted to the description of the dynamic hydro-economic model and the objectives of the water agency. Section 3 characterizes the feasible resource states and water policies under several constraints. An application illustrates the main results in Section 4. The last section concludes.

\section{The hydro-economic model}

\subsection{The resource dynamics}

An aquifer is described by its state variable (ie the height of water) $H(t) \in\left[0 ; S_{L}\right]$ at time $t$ where $S_{L}$ stands for the height of the ground surface. At $H(t)=0$, the aquifer is empty, at $H(t)=S_{L}$ the aquifer is full. The height of water increases with constant recharge $R>0$ and decreases because of extraction $W(t)$ dedicated to agriculture by $n$ farmers with $W(t)=\sum_{i=1}^{n} w_{i}(t)$. We assume that a proportion $\mu$ of the water used for irrigation comes back to the aquifer where $0<\mu<1$ stands for the non-absorption coefficient. Then total extraction is $(1-\mu) W$.

Based on Gisser and Sanchez (1980), the dynamics of the resource is

$$
\begin{aligned}
H(t+1) & =H(t)+\frac{R}{A S}-\frac{(1-\mu)}{A S} W(t), \\
H(0) & =H_{0},
\end{aligned}
$$

with $A$ stands for the area of the aquifer and $S$ the storage coefficient.

Eq (1) can be rewritten as

$$
H(t+1)=H(t)+\frac{1-\mu}{A S}\left(W_{R}-W(t)\right),
$$


where $W_{R}=\frac{R}{1-\mu}$ stands for the level of extraction which maintains constant the table water $(H(t+1)=H(t))$. If the extraction is too high $\left(W(t)>W_{R}\right)$, the net recharge is lower than the extraction and the height of the aquifer decreases.

\subsection{The water permit market}

A set of $n$ heterogeneous farmers use water denoted by $w_{i}$ from the aquifer to irrigate their crops. The individual profit of farmer $i$ is given by

$$
\pi_{i}(t)=p_{y} y_{i}(t)-c(t) w_{i}(t)-m(t)\left(w_{i}(t)-w_{i}^{-}(t)\right) .
$$

The first term of eq (3) refers to the total income with $p_{y}$ the price of the agricultural product (farmers are supposed to be price takers on the product market) and $y_{i}(t)$ the individual production which is assumed to be a quadratic form of the water use $w_{i}(t)$ as follows

$$
y_{i}(t)=a_{i} w_{i}(t)-\frac{b_{i}}{2} w_{i}^{2}(t)
$$

where $a_{i}>0$ and $b_{i}>0$ are technical parameters. Marginal productivity is positive and decreasing. Individual production reaches a maximum for $\overline{w_{i}}=a_{i} / b_{i}$ yielding $\overline{y_{i}}=a_{i}^{2} / 2 b_{i}=a_{i} \overline{w_{i}} / 2$. It implies that individual water extraction is bounded as follows: $w_{i} \in\left[0, \overline{w_{i}}\right]$. We deduce that the maximum amount of water consumption is $\bar{W}=\sum_{i=1}^{n} \overline{w_{i}}$ and the maximum amount of production is then $\bar{Y}=\sum_{i=1}^{n} \overline{y_{i}}$. Hence farmers can be ranked according their efficiency $\bar{y}_{1}>\bar{y}_{2}>\ldots>\bar{y}_{n}$. Farmer $n$ is the least efficient while farmer 1 is the most productive.

The second term of eq (3) refers to the extraction cost. The unitary cost $c(t)$ is given by

$$
\begin{aligned}
c(t) & =c_{1}\left(S_{L}-H(t)\right), \\
& =c_{0}-c_{1} H(t) .
\end{aligned}
$$

where $c_{0}=c_{1} S_{L}$ stands for a fixed cost and $c_{1}$ is the marginal pumping cost. The unitary cost is the same at each point of the aquifer. It increases with the diminution of the water table. When the height of the water table is at its maximum, the unitary cost is nul (Rubio and Casino, 2001).

The third term of eq (3) refers to the transferable permit market whose the unitary price is $m(t)$. It is assumed that the water extraction is managed 
by a water agency which allocates transferable water permits to the $n$ farmers at the beginning of each period $t$. After receiving their free of charge water entitlements $w_{i}^{-}(t)$ at each period, farmers decide whether to buy or sell water permits to other farmers, based on their annual water uses $w_{i}(t)$. It is assumed that water permits are not transferable through time, implying that banking or borrowing of water permits is forbidden.

The total water supply (ie the global amount of water allocated by the water agency) is equal to

$$
W(t)=\sum_{i=1}^{n} w_{i}^{-}(t)
$$

The total water quota demand depends on the optimal individual quotas, which emerge from the maximisation of individual profits

$$
\max _{w_{i}} \pi_{i}(t)
$$

First order conditions give the optimal individual water demand

$$
w_{i}^{*}(t)=\left(\frac{a_{i}}{b_{i}}-\frac{c_{0}}{p_{y} b_{i}}-\frac{m(t)}{p_{y} b_{i}}\right)+\frac{c_{1}}{p_{y} b_{i}} H(t) .
$$

We deduce the aggregate water demand ${ }^{1}$

$$
W^{*}(t)=\sum_{i=1}^{n} w_{i}^{*}(t)=\bar{W}-\beta \frac{c_{0}}{p_{y}}-\beta \frac{m(t)}{p_{y}}+\beta \frac{c_{1}}{p_{y}} H(t),
$$

with

$$
\bar{W}=\sum_{i=1}^{n} \overline{w_{i}} ; \beta=\sum_{i=1}^{n} \frac{1}{b_{i}} .
$$

The clearing market condition on the water market implies equality between water supply and demand

$$
W(t)=\bar{W}-\beta \frac{c_{0}}{p_{y}}-\beta \frac{m(t)^{*}}{p_{y}}+\beta \frac{c_{1}}{p_{y}} H(t) .
$$

\footnotetext{
${ }^{1}$ Simple manipulations give the irrigation water demand function of Gisser and Sanchez (1980) $W=g-k p_{w}$ with $g=\bar{W}, k=\beta / p_{y}$ and $p_{w}$ the price of water.
} 
We deduce the equilibrium water price $m^{*}(t)$

$$
m^{*}(t)=\frac{p_{y}}{\beta}(\bar{W}-W(t))-c_{0}+c_{1} H(t) .
$$

This analytical expression of $m^{*}(t)$ confirms the economic intuitions with $\frac{\partial m^{*}}{\partial W}<0$ and $\frac{\partial m^{*}}{\partial H}>0$. An increase in the water supply faced to an unchanged demand implies a decrease in the water price. When the height of the water table is high, water extraction increases and thus the demand of permits, pushing up the water price.

\section{The water agency constraints}

We consider a management strategy of the water agency in a food security context. In other words, the total production generated by the $\mathrm{n}$ farmers has to fit with the food security goal. Since water is a limiting resource for farmers, the objective of the water agency can be in conflict with the agricultural production objectives. The section shows how the quota market and the food security constraints implies conditions on the water extraction and the water resource.

\subsection{The water permit price constraint}

If a positive permit demand exists, then the price of the water permit $m^{*}(t)$ is positive

$$
0 \leq m^{*}(t)
$$

This positivity condition on $m^{*}(t)$ yields a state-control constraint

$$
W(t) \leq \bar{W}-\frac{\beta c_{0}}{p_{y}}+\frac{c_{1} \beta}{p_{y}} H(t) .
$$

By denoting the above function by $W_{M}$, it implies

$$
W(t) \leq W_{M}(H(t))
$$

The tradable water permit constraint entails a higher limit on the value of the total water extraction $W(t)$. This superior bound is an increasing function of the state variable $H(t)$. This bound depends on the economic parameters of farmers and on the price of agricultural product. 


\subsection{The food security constraint}

To deal with agriculture agency objectives of food security, the aggregate production of the agricultural sector has to satisfy a minimum threshold

$$
Y_{\text {lim }} \leq Y^{*}(t)
$$

with the aggregated production $Y^{*}(t)=\sum_{i=1}^{n} y_{i}^{*}(t)$

By substituting $m^{*}$ (eq 12) within $w_{i}^{*}$ (eq 8), we obtain

$$
w_{i}^{*}(t)=\frac{1}{b_{i}}\left(a_{i}-\left(\frac{\bar{W}-W(t)}{\beta}\right)\right),
$$

and thus the optimal individual production becomes

$$
y_{i}^{*}(t)=\frac{1}{2 b_{i}}\left(a_{i}^{2}-\left(\frac{\bar{W}-W(t)}{\beta}\right)^{2}\right) .
$$

Summing the individual productions $\left(y_{i}^{*}(t)\right)$ yields the aggregated production

$$
Y^{*}(t)=\bar{Y}-\frac{1}{2 \beta}(\bar{W}-W(t))^{2},
$$

with $\bar{Y}=\sum_{i=1}^{n} \overline{y_{i}}$.

The aggregated production constraint $Y_{\text {lim }} \leq Y^{*}(t)$ implies thus

$$
Y_{l i m} \leq \bar{Y}-\frac{1}{2 \beta}(\bar{W}-W(t))^{2}
$$

bounding the water supply $W(t)$ by an inferior limit $W_{F S}$

$$
W_{F S} \leq W(t),
$$

where $W_{F S}$ is constant and independent from the state variable

$$
W_{F S}=\bar{W}-\sqrt{2 \beta\left(\bar{Y}-Y_{\lim }\right)} .
$$

Not surprisingly, the existence of $W_{F S}$ impose that the objective of production $Y_{\text {lim }}$ cannot exceed than its maximum value $\bar{Y}$. Moreover, the positivity of the food security constraint (ie $W_{F S} \geq 0$ ) yields a minimum threshold: $Y_{\lim } \geq Y_{\lim }^{\min }$ with $Y_{\lim }^{m i n}=\bar{Y}-\left(\bar{W}^{2} / 2 \beta\right)$. 


\subsection{The resource constraint}

The existence of the water permit price constraint $W(t) \leq W_{M}(H(t))$ and of the food security constraint $W_{F S} \leq W(t)$ limits the level of the water table. Combining eq (15) and eq (21) gives

$$
W_{F S} \leq W \leq W_{M}
$$

This yields a critical threshold on the water table

$$
H_{\lim } \leq H(t)
$$

where $H_{\text {lim }}$ is such that

$$
H_{l i m}\left(Y_{\lim }\right)=S_{L}-\frac{p_{y}}{c_{1} \beta} \sqrt{2 \beta\left(\bar{Y}-Y_{\lim }\right)}
$$

with $S_{L}=c_{0} / c_{1}$. Substitute the value of $Y_{\lim }^{\min }$ that ensures that the food security is binding $W_{F S} \geq 0$ implies a condition on the amount of resource threshold. It gives

$$
H_{l i m}^{\min }\left(Y_{\lim }^{\min }\right)=\frac{1}{c_{1}}\left(c_{0}-\frac{p_{y} \bar{W}}{\beta}\right) .
$$

The value of $H_{l i m}^{\min }$ is positive under the condition

$$
c_{0}>\frac{p_{y} \bar{W}}{\beta}
$$

Eq (25) states that the marginal extraction cost of the last unit of water $\left(c_{0}\right)$ is higher than the maximum value of marginal product (Rubio and Casino $(2001))^{2}$. A violation of the condition (25) means that the food security constraint associated to the minimum extraction is not a binding constraint for the resource. On contrary, when $Y_{\lim } \geq \bar{Y}-\frac{\beta}{2}\left(\frac{c_{0}}{p_{y}}\right)^{2}>Y_{\lim }^{\min }$, a positivity constraint on $H_{\text {lim }}$ holds. The next section shows how condition (25) impacts the set of quota supply of the water agency.

\footnotetext{
${ }^{2}$ The authors (pp 1123) derive a similar condition $c_{0} \geq g / k$ that eliminates the possibility of a corner solution in which $H \leq 0$.
} 


\subsection{The maximum food security objective}

Satisfying simultaneously the food security constraint $\left(W_{F S} \leq W(t)\right)$ and the equilibrium constraint $\left(W(t) \leq W_{R}\right)$ implies

$$
W_{F S} \leq W_{R}
$$

This condition means that if the food security is too demanding, the water extraction requiring for the demanding production is higher than the recharge of the aquifer. The water table decreases towards zero, and it is not possible to define any sustainable water extraction. This allows to define a maximum threshold $Y_{\text {lim }}^{\max }$ able to sustain a non-empty groundwater. This value is computed with the limit case, where the equilibrium water extraction $W_{R}$ and the food security constraint $W_{F S}$ are overlapped $\left(W_{F S}=W_{R}\right)$. We deduce then

$$
Y_{l i m}^{\max }=\bar{Y}-\frac{\left(\bar{W}-W_{R}\right)^{2}}{2 \beta} .
$$

We can note that $Y_{\text {lim }}^{\max }$ is below the maximum amount of production $\bar{Y}$ for a nul extraction cost. When the food security objective $Y_{\text {lim }}$ reaches its maximum $Y_{\text {lim }}^{\max }$, the groundwater height as well as the allowed extraction remain constant. Moreover, the consistency of $Y_{\text {lim }}^{\max }$ (ie $Y_{\text {lim }}^{\max } \geq Y_{\text {lim }}^{\min }$ ) implies a upper bound on the water height such that

$$
H_{\text {lim }}^{\max }\left(Y_{\text {lim }}^{\max }\right)=\frac{1}{c_{1}}\left(c_{0}-\frac{p_{y}\left(\bar{W}-W_{R}\right)}{\beta}\right) .
$$

\section{Results}

Taking into account the described hydro-economic model, we consider that the water agency implements a quota policy in a dynamic context which satisfies all the constraints. We characterize the sustainability of the system based on the concept of viability kernel. The viability kernel is the set of initial height of water for which exists at least one regime of quotas satisfying the constraints along time. This section aims at identifying the viability kernel and the associated viable quotas.

\subsection{Viability kernel}

The dynamics of the aquifer given by eq (1) is taken into account in combination with 
1. the water permit price constraint (15): $W(t) \leq W_{M}(H(t))$,

2. the food security constraint (21): $W_{F S} \leq W(t)$,

3. the resource constraint (24): $H(t) \geq H_{\text {lim }}$.

In a finite horizon context, the viability kernel can be formally defined as the set of initial situations $H_{0}$ such as it exists water extraction $W(t)$ and resources $H(t)$, satisfying the previous constraints, for any time between $t=0,1, \ldots T$.

We obtain the following proposition ${ }^{3}$

Proposition 1. Assuming that $W_{F S} \leq W_{R}$ and $Y_{\text {lim }}^{\min } \leq Y_{\text {lim }} \leq Y_{\text {lim }}^{\max }$, we obtain

- If $H(0)<H_{l i m}$ then no viability occurs Viab $=\emptyset$

- If $H(0) \geq H_{\text {lim }}$ the viability kernel is Viab $=\left[H_{\mathrm{lim}}, S_{L}\right]$

Proposition (1) shows that the viability of the quota management strategies depends on the initial amount of available water in the aquifer as compared with the minimum resource threshold $H_{\text {lim }}$ emerging from the amount of water extraction $W_{F S}$ needed to satisfy the food security constraints given by $Y_{\text {lim }}$.

We observe that two non viable cases can occur. The first situation emerges when the initial height of the water table $H_{0}$ is smaller than the tipping resource state $H_{\lim }$ and consequently does not belong to the viability kernel. The second case occurs when the objective of food production is too demanding. In this case, the water extraction $W_{F S}$ exceeds the water volume extraction $W_{R}$ which maintains constant the table water.

Figure (1) shows the viability kernel in the water table vs. water extraction space $(H, W)$. The equilibrium extraction level is represented by the horizontal straight line $W_{R}$. When water extraction is above $W_{R}$, the recharge of the aquifer cannot compensate the extraction, generating then a decrease of the water table. On contrary, the volume of the aquifer increases for lower extractions $\left(W(t)<W_{R}\right)$. The food security constraint is also represented by the horizontal straight line $W_{F S}$. The water permit constraint

\footnotetext{
${ }^{3}$ The proof is given in Appendix.
} 
is represented by the increasing linear function $W_{M}$. The intercept with the $\mathrm{Y}$-axis depends on the values of the parameters given by condition (25). The intersection of the two constraints $W_{M}$ and $W_{R}$ gives the critical stock $H_{\text {lim }}$. The viability domain corresponds to the area which lies above the food security constraint and below the water permit constraint $W_{M}$. In this area, the viability domain allows increasing or decreasing water dynamics depending on whether the system is above or below the sustainable water extraction $W_{R}$.

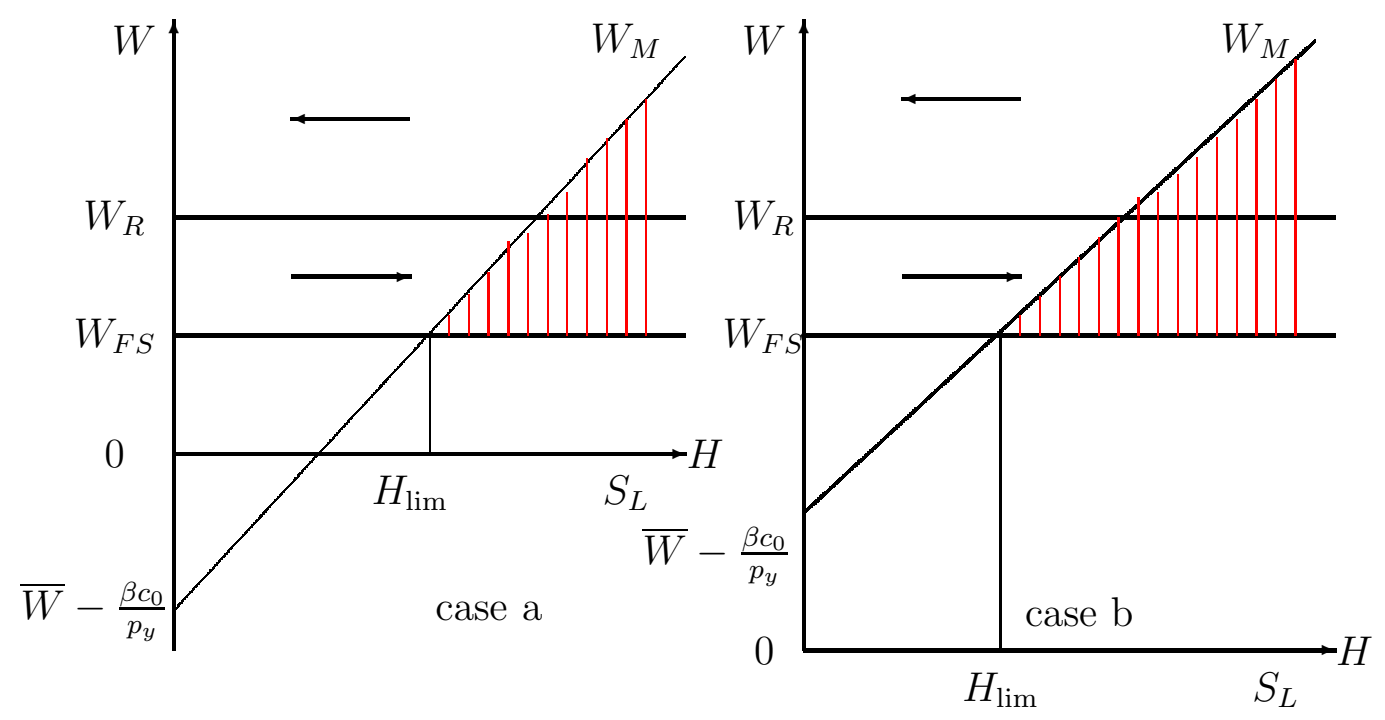

Figure 1: Viability domain when $c_{0}>\frac{p_{y} \bar{W}}{\beta}$ (case a) and when $c_{0}<\frac{p_{y} \bar{W}}{\beta}$ (case b).

\subsection{Viable water quotas}

We derive the viable water quotas from proposition (1). The viable controls have to maintain the water table of the aquifer within the viability kernel using the dynamic programming structure depicted in Doyen and DeLara (2010). In other words, the viable quotas $W(t)$ have to comply with the additional intertemporal condition $H_{\lim } \leq H(t+1)$. Using eq (1), we obtain

$$
W(t) \leq W_{R}+\frac{A S}{(1-\mu)}\left(H(t)-H_{\lim }\right) .
$$

Denoting by $W_{D}$ the above function, the dynamic context of the resource threshold yields

$$
W(t) \leq W_{D}(H(t))
$$


This dynamic constraint leads to a superior bound for the water extraction $W(t)$. This superior limit is an affine and increasing function of the state variable $H(t)$.

The comparison between the slopes of $W_{D}(H(t))$ and $W_{M}(H(t))$ shows $^{4}$ that the dynamic viability constraint $W_{D}(H(t))$ is binding and reduces the viability domain under the condition on the marginal pumping cost:

$$
c_{1}>\left(\frac{A S}{1-\mu}\right)\left(\frac{p_{y}}{\beta}\right) .
$$

Based on the extraction cost function (eq 5), a high value of $c_{1}$ means a low extraction cost. This creates incentives for farmers to increase their water consumption to get higher payoffs. It adds a dynamic constraint of the water quota setting for the water agency. It means that the viability domain is reduced and the room for manoeuvre to manage the aquifer is also reduced. When condition (30) is not satisfied, $W_{D}(H(t))$ is not active and the viable quotas will solely depend on $W_{M}(H(t))$ and $W_{F S}$.

We are then able to specify the viable quotas $W$ associated to the viable water tables.

Proposition 2. Considering that $W_{F S} \leq W_{R}$, the viable quotas associated to Viab $=\left[H_{\lim }, S_{L}\right]$ are

$$
W^{V i a b}=\left[W_{F S}, \min \left(W_{M}, W_{D}\right)\right] .
$$

Figure 2 displays the viable quota policies when the viability kernel is not empty and when condition (30) holds in the level state-control $(H, W)$ space. The dynamic constraint $W_{D}$ is represented by an increasing linear function with a negative intercept with the Y-axis for $H_{\lim }>\frac{(1-\mu) W_{R}}{A S}$. This configuration also satisfies condition (25). Figure 3 shows a case in which the quota dynamic constraint in not active. Based on numerical examples, the next section will show how such both configurations are possible.

\footnotetext{
${ }^{4}$ See appendix.
} 


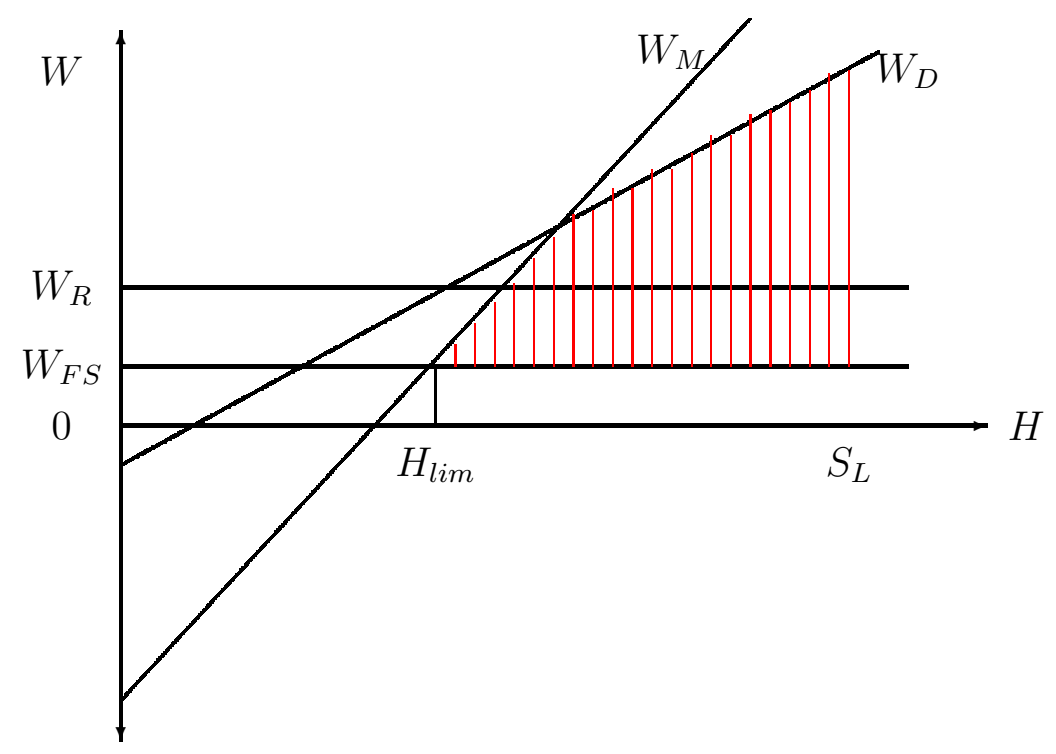

Figure 2: Viable water quotas when the quota dynamic constraint is active under the condition $c_{1}>\left(\frac{A S}{1-\mu}\right)\left(\frac{p_{y}}{\beta}\right)$.

\section{Numerical illustration}

The numerical example is based on the case study of Gisser and Sanchez (1980) adapted to deal with heterogeneous farmers.

\begin{tabular}{cccc} 
Parameters & Description & units & value \\
\hline$\mu$ & Return flow coefficient & Unitless & 0.27 \\
\hline$R$ & Natural recharge & ac ft $/ \mathrm{yr}$ & 173000 \\
\hline$A S$ & Aquifer area times storativity & ac ft/yr & 1500 \\
\hline$c_{0}$ & fixed cost & $\$ / \mathrm{ac} \mathrm{ft}$ & 125 \\
\hline$c_{1}$ & Pumping costs & $\$ /$ ac ft per foot of lift & 0.035 \\
\hline$H_{0}$ & Initial water table elevation & feet above sea level & 3400 \\
\hline$a$ & production coefficient & $\$ / \mathrm{ac} \mathrm{ft}$ & 96.218676 \\
\hline$b$ & squared production coefficient & $\$ / \mathrm{ac} \mathrm{ft}$ & 0.0204562 \\
\hline$n$ & number of farmers & Unitless & 100 \\
\hline$p_{y}$ & crop price & $\$ / \mathrm{ac} \mathrm{ft}$ & 1.5 \\
\hline
\end{tabular}

Gisser and Sanchez (1980) specified an aggregate linear water demand $W=g-k p_{w}$ with $g, k>0$ (measured in ac ft/yr) and $p_{w}$ the water price 


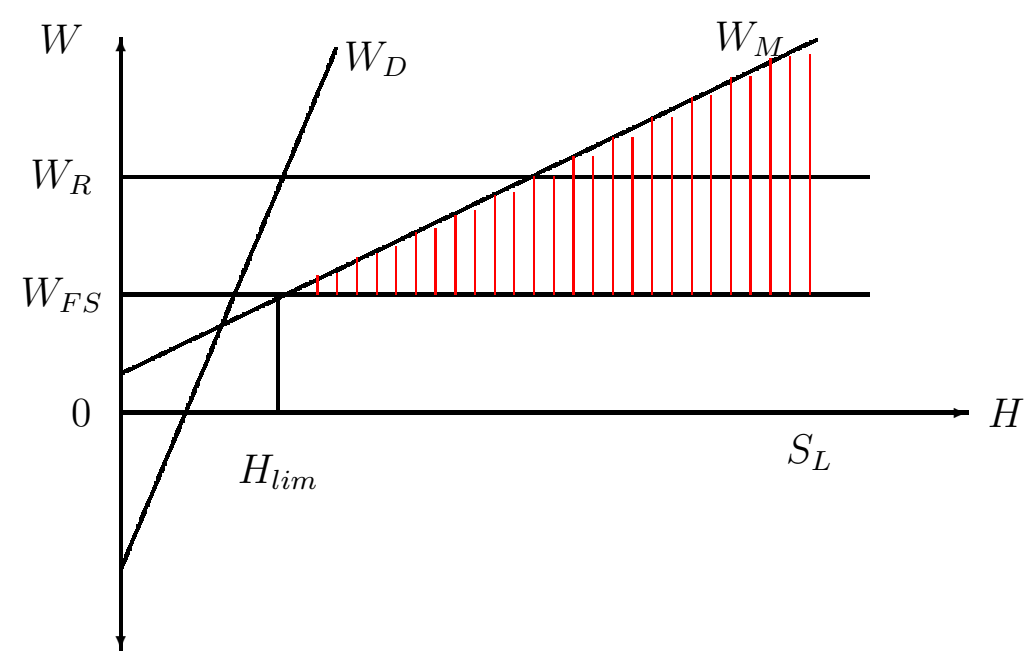

Figure 3: Viable water quotas when the quota dynamic constraint is not active under the condition $c_{1}<\left(\frac{A S}{1-\mu}\right)\left(\frac{p_{y}}{\beta}\right)$.

(in $\$ / \mathrm{ac} \mathrm{ft}$ ). By identification with our model, and in particular eq (9) with $m(t)=0$, the intercept of the demand-for-water function is $g=\bar{W}$ and the slope of the demand-for-water function $k=\frac{\beta}{p_{y}}$ with $\bar{W}$ and $\beta$ given by eq (10).

Using the values of $a, b, n$ and $p_{y}$ gives the value of Gisser and Sanchez: $g=470365$ and $k=3259$. We have to note that $H_{0}$ is closed to the height of the ground surface $S_{L}=c_{0} / c_{1}$. Heterogeneity between the farmers is introduced through the values of $b_{i}$ as a uniform random variable over the interval $[b *(1-\delta), b *(1+\delta)]$ with a dispersion rate $\delta=10 \%$. Compared to Gisser and Sanchez's case study, we choose a lower value of $A S$ to reduce the simulation horizon.

Based on these numerical specifications, it turns out that both conditions (25) and (30) are not satisfied. This configuration refers to case 3 where the dynamic constraint is not active. In other words, since $W_{R}=236986 \mathrm{ac} \mathrm{ft} / \mathrm{yr}$ is higher than $W_{F S}=203617 \mathrm{ac} \mathrm{ft} / \mathrm{yr}$, the water agency can implement at each period a quota policy that belongs to the viability kernel.

The food security constraint corresponds to the production $Y_{\text {lim }}=15352336$ (in lbs) and a threshold resource $H_{\text {lim }}=1233$ feet which is higher than $\frac{(1-\mu) W_{R}}{A S}$. Figure 4 displays an associated viable trajectory for the water table 
$H(t)$, the quotas $W(t)$, the price quota $m(t)$ and the mean individual profit $\sum_{n} \frac{\pi_{i}(t)}{n}$.

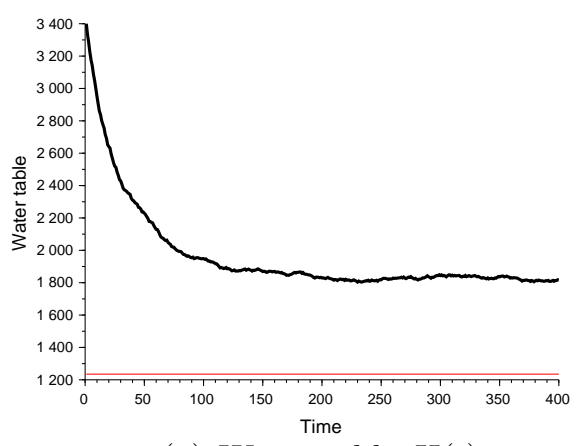

(a) Water table $H(t)$

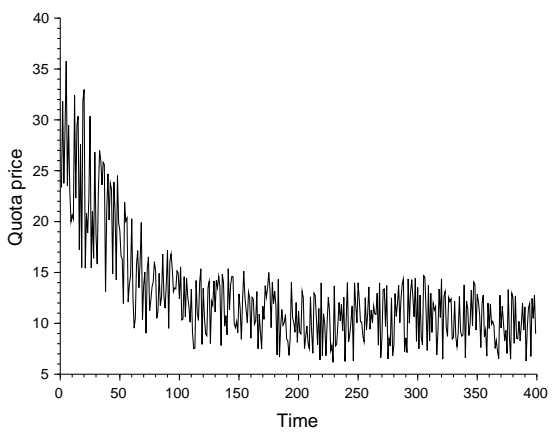

(c) Price quota $m(t)$

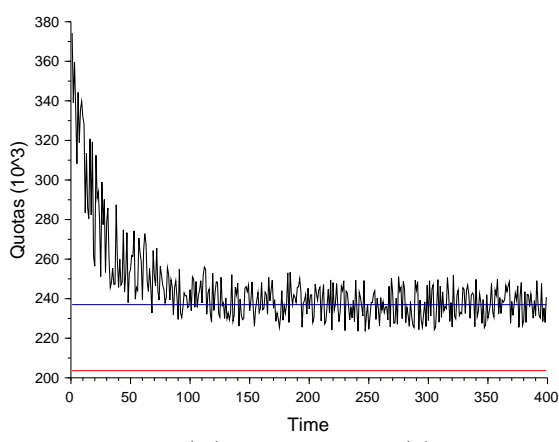

(b) Quotas $W(t)$

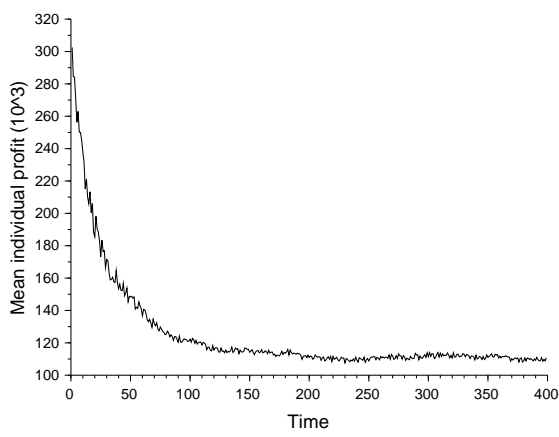

(d) Mean profit $\sum_{n} \frac{\pi_{i}(t)}{n}$

Figure 4: Trajectories of the water table $H(t)$, the quotas $W(t)$, the price quota $m(t)$ and the mean individual profit $\sum_{n} \frac{\pi_{i}(t)}{n}$. In figure (a), the red line stands for the $H_{l i m}=1233$ f. In figure (b), the red line stands for the food security constraint $W_{F S}=203617 \mathrm{ac} \mathrm{ft} / \mathrm{yr}$ and the blue line represents $W_{R}=236986 \mathrm{ac} \mathrm{ft} / \mathrm{yr}$.

We provide a second simulation illustration, in which all the constraints are binding as explained in case 2. For that, we consider some new values for the parameters such that (25) and (30) are satisfied. It leads us to set $c_{0}=1250$ and $c_{1}=0.35$ such that $S_{L}$ remains constant.

We also consider $b=0.011$ which modifies the intercept and the slope of the demand-for-water function as follows $g=874715$ and $k=6060$. For these new values, the food security constraint corresponds to the production $Y_{\text {lim }}=17742213 \mathrm{lbs}$ while its maximum value is $Y_{\text {lim }}^{\max }=19717481 \mathrm{lbs}$. 
Increasing $c_{1}$ and decreasing $b$ means that the pressure on the resource is reinforced due to a larger demand and the smaller cost of extraction. Both effects imply a higher constraint on the resource threshold value $H_{\text {lim }}=3257$ f. Hence for a same food constraint, the resource threshold is $60 \%$ higher than in the previous case. Figure 5 displays an associated viable trajectory for the water table $H(t)$, the quotas $W(t)$, the price quota $m(t)$ and the mean individual profit $\sum_{n} \frac{\pi_{i}(t)}{n}$.

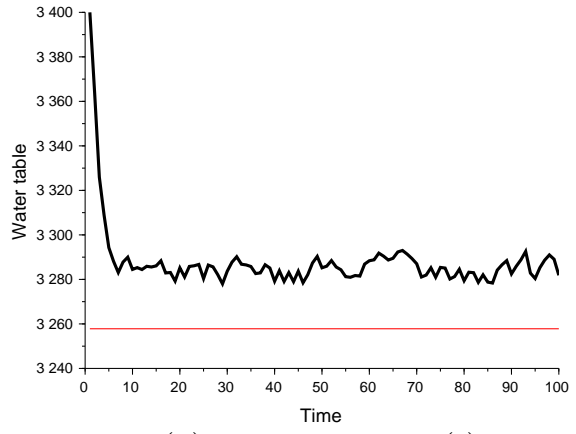

(a) Water table $H(t)$

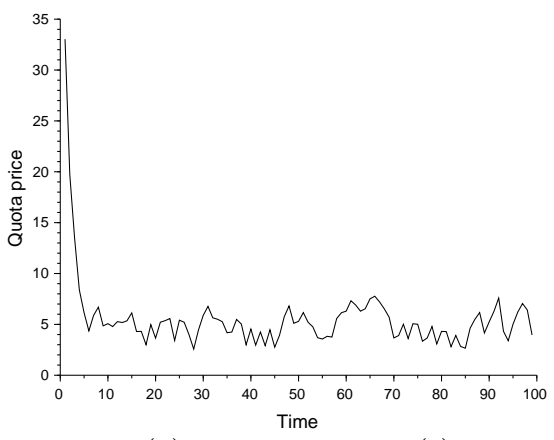

(c) Price quota $m(t)$

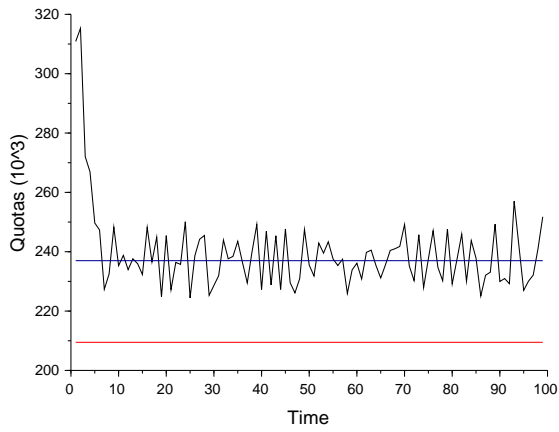

(b) Quotas $W(t)$

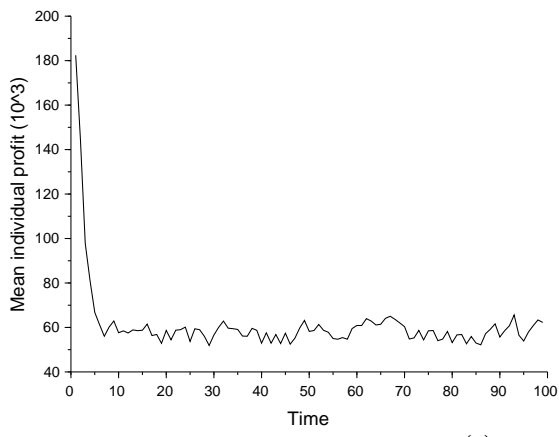

(d) Mean profit $\sum_{n} \frac{\pi_{i}(t)}{n}$

Figure 5: Trajectories of the water table $H(t)$, the quotas $W(t)$, the price quota $m(t)$ and the mean individual profit $\sum_{n} \frac{\pi_{i}(t)}{n}$. In figure (a), the red line stands for the $H_{l i m}=3257$ f. In figure (b), the red line stands for the food security constraint $W_{F S}=203617 \mathrm{ac} \mathrm{ft} / \mathrm{yr}$ and the blue line represents $W_{R}=236986 \mathrm{ac} \mathrm{ft} / \mathrm{yr}$. 


\section{Conclusion}

This paper examines the problem of groundwater management in irrigated agriculture. A water agency is assumed to allocate a total amount of water to farmers using tradable permits. Our framework emphasizes how the water agency deals with the constraint of food security defined as a objective of a minimum amount of agricultural production for the whole agricultural sector. In a dynamic hydro-economic model, we determine the feasibility conditions under which the water agency ensures the joint sustainability of the resource and the agricultural activity.

Our results show that the food security constraint entails a threshold on the water resource. When the food security constraint is too demanding with respect to the net recharge, or when the initial level of the water table is below the threshold value, the over-exploitation of the aquifer leads to its depletion. Our results also show the conditions under which the water agency can select different amount of water quota among a viable set of regulation policies. The implementation of a tradable water permits ensures the economic efficiency in the use of the resource and gives flexibility to the water agency in the design of its policies. Numerical examples based on the data of Gisser and Sanchez (1980) show illustrations of the theoretical results of the paper.

Future extensions could be considered. A first one consists in introducing an individual constraint on farmers in terms of warranted payoffs. By dealing with an aggregate food security objective together with individual constraints for heterogenous farmers, the water agency will face equity and acceptability issues when setting the quota supply and the initial allocation of the water permits (Ballestero et al, 2002). A second extension relies on the introduction of stochasticity on the natural recharge rate of the aquifer. De Frutos Cachorro et al (2014) show that such an uncertainty can create incentives for the water agency to allow more extraction in the long run than in the short run. It suggests the use of robust viability theory to address dynamical control problems under constraints with uncertainty (Doyen and De Lara, 2010; Regnier and De Lara, 2015).

\section{Acknowledgements}

This study has been carried out with financial support from the French National Research Agency (ANR) as part of the project ADAPTEAU (ANR- 
11-CEPL-008) and in the frame of the Cluster of Excellence COTE (ANR10-LABX-45).

\section{References}

Aubin J-P (1990), A survey of viability theory, The SIAM Journal on Control and Optimization 28 (4) (1990) 749-788.

Ballestero E., S. Alarcon and A. Garcia-Bernabeu (2002), Etablishing politically feasible water markets: a multi-criteria approach, Journal of Environmental Management, 65:411-429.

Booker J, Howitt R, Michelsen A, and Young R, (2012) Economics and the modeling of water resources and policies, Natural resource modeling, 25(1):168-218.

Branch T (2008) How do individual transferable quotas affect marine ecosystems? Fish and Fisheries 9:1-19

Clarke F.H., YU.S. Ledayev, R.J. Stern, P.R. Wolenski, (1995) Qualitative properties of trajectories of control systems: a survey, Journal of Dynamical and Control Systems, 1:1-48.

Chu C, (2009) Thirty years later: the global growth of ITQs and their influence on stock status in marine fisheries, Fish and Fisheries 10(2):217230.

Doyen, L. and M. De Lara (2010) Stochastic viability and dynamic programming, Systems and Control Letters 59(10):629-634.

Doyen, L. and J-C. Pereau (2012) Sustainable coalitions in the commons, Mathematical Social Sciences 63(1):57-64.

de Frutos Cachorro J, Erdlenbruch K, and Tidball M. (2014) Optimal adaptation strategies to face shocks on groundwater resources, Journal of Economic Dynamics and Control, 40:134-153.

FAO (2014) Building a common vision for sustainable food and agriculture: Principes and Approaches, Rome.

Gisser, M., and Sanchez, D.A., (1980) Competition versus optimal control in ground water pumping, Water Resource Research 31:638-642.

Knapp K, Weinberg M, Howitt R and Posnikoff J (2003) Water transfers, agriculture and qroundwater management: a dynamic economic analysis, Journal of Environmental Management, 67:291-301.

Koundouri P. (2004) Current issues in the economics of groundwater resource management, Journal of Economic Survey, 18(5):703-740 
Latinopoulos D. and E.S. Sartzetakis (2015) Using Tradable Water Permits in Irrigated Agriculture, Environmental and Resource Economics, 60(3):349370 .

Madani K, and Dinar A. (2013) Exogenous regulatory institutions for sustainable common pool resource management: Application to groundwater, Water Resources and Economics, 2-3:57-76

Martinet V, O. Thébaud, L. Doyen, (2007) Defining viable recovery paths toward sustainable fisheries, Ecological Economics 64(2):411-422.

Péreau, J.-C., Doyen, L., Little, L., Thébaud, O., (2012) The triple bottom line: meeting ecological, economic and social goals with individual transferable quotas. Journal of Environmental and Economics Management, 63:419-434.

Provencher B. (1993) A Private Property Rights Regime to replenish a Groundwater Aquifer, Land Economics, 69(4):335-40.

Regnier E. and M. De Lara (2015) Robust viable analysis of a harvested ecosystem model, Environmental Modeling and Assessment, 20(6):687-698.

Roumasset J. and Wada C. (2012) The economics of grounwater, WP 2012-4, UHERO-University of Hawai.

Rubio S.J. and Casino B. (2001) Competitive versus Efficient Extraction of a Common Property Resource: The Groundwater Case. Journal of Economic Dynamics and Control, 25(8), 1117-1137.

Tomini A. (2014) Is the Gisser and Sanchez model too simple top discuss the economic relevance of groundwater management? Water Resources and Economics, 6:18-29

Wada Y., LPH van Beek, CM van Kempen, JWTM Reckman, S Vasak and MFP Bierkens (2010) Global depletion of groundwater resources, Geophysical Research Letters, 37, L20402.

WWAP (United Nations World Water Assessment Programme). 2015. Water for a Sustainable World. Paris, UNESCO.

\section{Appendix}

\subsection{Proof viability kernel}

Proof: Consider the dynamics

$$
H(t+1)=H(t)+\frac{1-\mu}{A S}\left(W_{R}-W(t)\right),
$$


with $W_{R}=\frac{R}{1-\mu}$.

We first show that $W_{F S} \leq W_{R}$ implies $V i a b=\left[H_{\text {lim }},+\infty[\right.$. Assume that $H_{0} \geq H_{\text {lim }}$, choose $W=W_{F S}$ then

$$
H+\frac{1-\mu}{A S}\left(W_{R}-W\right)=H+\frac{1-\mu}{A S}\left(W_{R}-W_{F S}\right) \geq H \geq H_{\mathrm{lim}} .
$$

Hence $\left[H_{\lim },+\infty\left[\right.\right.$ is viable and $V i a b=\left[H_{\text {lim }},+\infty[\right.$.

Now if $W_{F S}>W_{R}$, we show by forward induction that

$$
\begin{aligned}
& \left.H(1)=H(0)-\left(\frac{1-\mu}{A S}\right)\left(W_{F S}-W_{R}\right)\right), \\
& \left.H(2)=H(0)-2\left(\frac{1-\mu}{A S}\right)\left(W_{F S}-W_{R}\right)\right), \\
& \left.H(t)=H(0)-t\left(\frac{1-\mu}{A S}\right)\left(W_{F S}-W_{R}\right)\right) .
\end{aligned}
$$

Hence $\exists t^{*}$ such that $H\left(t^{*}\right)<H_{\lim }$, it implies that $V i a b=\emptyset$.

\subsection{Dynamic constraint $W_{D}$}

The constraint on the state variable $H_{\text {lim }} \leq H(t+1)$ implies

$$
\begin{aligned}
H_{\text {lim }} & \leq H(t)+\frac{R}{A S}-\frac{(1-\mu)}{A S} W(t), \\
& \Longleftrightarrow W(t) \leq W_{R}-\frac{A S}{(1-\mu)} H_{l i m}+\frac{A S}{(1-\mu)} H(t) .
\end{aligned}
$$

By denoting $W_{D}=W_{R}-\frac{A S}{(1-\mu)} H_{l i m}+\frac{A S}{(1-\mu)} H(t)$ it gives $W(t) \leq W_{D}(H(t))$ We look at the conditions depending on the sign of $W_{M}-W_{D}$ under which this dynamic constraint is binding and reduces the viability kernel. By definition, $W_{D}\left(H_{\text {lim }}\right)=W_{R}$ and since $W$ is bounded by $W_{R}$, it implies that for $H=H_{\text {lim }}$

$$
W_{M}\left(H_{l i m}\right)<W_{D}\left(H_{l i m}\right) .
$$

It yields

$$
\bar{W}-W_{R}<\frac{\beta}{p_{y}}\left(c_{0}-c_{1} H_{l i m}\right) .
$$

The expression of $W_{M}-W_{D}$ is given by

$$
W_{M}-W_{D}=\bar{W}-W_{R}-\frac{\beta c_{0}}{p_{y}}+\frac{c_{1} \beta}{p_{y}} H-\frac{A S}{1-\mu}\left(H-H_{l i m}\right) .
$$


Using (34), it gives

$$
\begin{aligned}
W_{M}-W_{D} & <\frac{\beta}{p_{y}}\left(c_{0}-c_{1} H_{l i m}\right)-\frac{\beta c_{0}}{p_{y}}+\frac{c_{1} \beta}{p_{y}} H-\frac{A S}{1-\mu}\left(H-H_{l i m}\right), \\
W_{M}-W_{D} & <\frac{c_{1} \beta}{p_{y}}\left(H-H_{l i m}\right)-\frac{A S}{1-\mu}\left(H-H_{l i m}\right) .
\end{aligned}
$$

When $H>H_{\text {lim }}$ the condition ensuring $W_{M}-W_{D}>0$ is

$$
c_{1}>\left(\frac{A S}{1-\mu}\right)\left(\frac{p_{y}}{\beta}\right) \text {, }
$$

and corresponds to eq (30) in the text. 


\title{
Cahiers du GREThA \\ Working papers of GREThA
}

\section{GREThA UMR CNRS 5113}

\author{
Université de Bordeaux \\ Avenue Léon Duguit \\ 33608 PESSAC - FRANCE \\ Tel : +33 (0)5.56.84.25.75 \\ Fax : +33 (0)5.56.84.86.47 \\ http://gretha.u-bordeaux.fr/
}

\begin{abstract}
Cahiers du GREThA (derniers numéros - last issues)
2015-34: CAPARROS Alejandro, PEREAU Jean-Christophe: Multilateral versus sequential negotiations over climate change

2015-35: BECUWE Stéphane, BLANCHETON Bertrand, ONFROY Karine: Données du commerce extérieur de la France entre 1836 et 1938 - Base Montesquieu

2016-01 : CHENAF-NICET Dalila, ROUGIER Eric : The effect of macroeconomic instability on FDI flows: A gravity estimation of the impact of regional integration in the case of EuroMediterranean agreements

2016-02 : COMBARNOUS François, DEGUILHEM Thibaud : Urban labor market revisited: Why quality of employment matters in Bogota

2016-03 : DEGUILHEM Thibaud, FRONTENAUD Adrien : Régimes de qualité de l'emploi et diversité des pays émergents

2016-04 : BENABDEJLIL Nadia, LUNG Yannick, PIVETEAU Alain : L'émergence d'un pôle automobile à Tanger (Maroc)

2016-05: MAICHANOU Ahamadou, La micro-assurance agricole indicielle: raisons et conditions d'exercice au Niger

2016-06: MAICHANOU Ahamadou, Déterminants d'emprunt et de risque de crédit des ménages ruraux au Niger

2016-07: BERTHE Alexandre, Mesurer les inégalités d'accès à l'eau et à l'assainissement dans le Nord et le Nordeste du Brésil : quels enseignements en matière de justice sociale?

2016-08 : LORENZON Emmanuel, Collusion with a Greedy Center in Position Auctions

2016-09: DELFAUD Pierre, Retour sur une expérience unique d'interventionnisme en économie de marché: La Politique agricole commune européenne (1955-2015)

2016-10: MUTASCU Mihai, PEREAU Jean-Christophe, URSU Eugen: A Wavelet Analysis of the Environmental Kuznets Curve in France

2016-11 : LISSONI Francesco : Migration and Innovation Diffusion: An Eclectic Survey

2016-12 : BONIN Hubert : Les paradoxes de l'économie maritime française au début du XXIe siècle

2016-13 : CASTIGLIONESI Fabio, NAVARRO Noémi : (In)Efficient Interbank Networks
\end{abstract}

La coordination scientifique des Cahiers du GREThA est assurée par Emmanuel PETIT. La mise en page est assurée par Julie VISSAGUET 